\title{
Understanding The Process Model Of Leadership: Follower Attribute Design And Assessment
}

Absael Antelo, University of the Incarnate Word, USA

Richard L. Henderson, University of the Incarnate Word, USA

Norman St. Clair, University of the Incarnate Word, USA

\begin{abstract}
Early leadership studies produced significant research findings that have helped differentiate between leader and follower personal attributes and their consequent behaviors (SEDL, 1992), but little attention was given to the follower's contribution to the leadership process. This study represents a continuation of research by Henderson, Antelo, \& St. Clair on the process model of leadership begun in 2006. Initial research efforts concentrated on leader-held attributes that contribute to the process. Research in work group motivation indicates that individual worker motivation influences performance and productivity; thus, leaders seek to understand what motivates followers to reach extraordinary performance. Employees, however, respond in a variety of ways to their jobs and their organizations' practices. A paramount task for the leader is to determine what factors impact work motivation. The idea is based on the premise that individual attributes are brought to the workplace by each member of the group. The concept of individual differences involves personal needs, values, attitudes, interests, and abilities people bring to their jobs. Job characteristics refer to the nature of the position determining its limitations and challenges. Organizational practices are the rules, policies, managerial practices, and reward systems of the organization. This complexity is increased with the construct of motivation, which is understood as the process that moves a person toward a goal. In consequence, "motivated behaviors are voluntary choices controlled by the individual employee." The leader, therefore, attempts to influence the factors that motivate employees. (Authors)
\end{abstract}

Keywords: Leadership; Process theory; Leadership Attributes; Leadership Instrumentation; Leadership Attribute Assessment

\section{INTRODUCTION}

$\mathscr{I}$ n a longitudinal field study, researchers tested follower developmental attributes as predictors of transformational leadership. They included a sample of 54 military units and their leaders, in which there were 90 direct followers and 724 indirect followers. Findings indicated that followers' initial developmental levels, as expressed by the initial level of their self-actualization needs, internalization of the organization's moral values, collectivistic orientation, critical-independent approach, active engagement in the task, and self-efficacy, positively predicted transformational leadership among indirect followers, whereas these relationships were negative among direct followers (Dvir \& Shamir, 2003).

In addition, literature indicates that researchers focus primarily on the traits and behaviors of charismatic leaders and the corresponding effects of these leaders have on their followers. However, one issue that has been neglected is the disposition of the followers who develop charismatic relationships with their leaders. Ehrhart and Klein (2001) conducted a laboratory study in which participants' values investigated this problem and personality dimensions were used to predict participants' preferences for charismatic leadership versus relationship-oriented and task-oriented leadership styles. Results of this study suggest evidence that values and personality were useful in predicting leadership preferences (Ehrhart \& Klein, 2001). 
Indeed, early conceptualizations of leadership are challenged today. The interactions between leaders and followers represent a new view of leading as a process that takes place as a result of these interactions. Leadership then is defined as a "dynamic relationship based on mutual influence and common purpose between leaders and collaborators in which both are moved to higher levels of motivation and moral development as they affect real, intended change" (Freiberg \& Freiberg, 1996, p. 298). A close inspection of this concept shows that leadership is a process involving both mutual and collaborative relationships. Relationships imply connection with people; mutual involves sharing with others; and collaborative means people working together in the interest of goal attainment. This kind of collaboration also implies a high level of commitment and motivation, not only on the part of the followers, but also on the part of the leader. This definition of leadership contends that the leader is influenced by the collaborators while they work together to achieve a significant goal.

\section{STATEMENT OF THE PROBLEM AND THE SUPPORTING LITERATURE}

Researchers and practitioners of organizational leadership are now directing their efforts to find new and more promising approaches to improve performance and team effectiveness. This new approach makes it imperative to study followers within a leadership process, based on the understanding that both the leader and the follower influence the process.

Leadership seems to be that process which emerges from interactions between the leader and the follower. This interaction may have varying degrees of the quality and effectiveness that help leaders and followers accomplish challenging and demanding organizational goals. At the same time, goals may not reach the level of expectation due to the low effectiveness of their relationships and failed interaction. The resulting issue is a concern about which attributes a person should have as a follower to engage in the leadership process. Many leaders become effective due to the quality of the followers. Others maintain the traditional views of a leader as a taskmaster and one who relies on situational variables and contingency approaches produced by early research to guide their performance.

Existing evidence on leadership as a process will be discussed to justify the purpose of, and need for, the current research project. During the industrial era, leadership was casted within a dyadic supervisor/subordinate relationship. As a result, any person having a supervisory position was identified as a leader. It was further assumed that the supervisors had singular and specific abilities and traits that set them apart from followers. But, today we are experiencing the realities of a different paradigm. Leadership can alternatively be defined as a political process. As it is the case with social movements, many argue that the common good emerges from chaotic, reciprocal interaction among people with potentially conflicting goals, values, and ideas. This phenomenology can be described as behaviors consisting of coalitions, bargaining, conflicting actions over scant resources, and other mutual influences people engage in socially constructed realities (Barker, 1997). This is an approach, though not necessarily a rational one, that signals the presence of some rules being applied to facilitate such processes. One could observe these rules in the criteria that are established to reach mutual agreements in the interest of attaining a shared goal or common good.

At this point, it is clear to assert that there are some critical missing evidences that prevent the understanding of leadership as a process. First of all, the inherent contention of such a process is that it "... must be conceptualized before the leadership relationships and the leadership roles are conceived" (Barker, 1997, p. 343). This is consistent with earlier writings on the subject. Burns wrote: “. . . if we know too much about our leaders, we know far too little about leadership?" (Barker, 1978, p.343). In addition, most authors are unaware of their dependence on a very old paradigm of leadership that is beginning to conflict with the realities of today's modern world (Barker, 1997). This is a particularly a painful gap because it may imply that we are using old theoretical frameworks to solve new problems. Actually, in the literature, there are numerous criticisms that indicate the transition of the very nature of leadership. In educational circles, it is found that not defining leadership has been an accepted trend among scholars who discuss the field of leadership (Barker, 1997, p. 343). Barker's research also indicated that definitions used to define leadership are contradictory, the models are discrepant, and the content of leadership is confused with the nature of leadership. In other words, the study of leadership as an academic discipline is in shambles. Sources of this confusion must lie in inappropriate application of basic assumptions; i.e., the use of old ideas to explain new phenomena (Barker, 1997). 
The issue of culture as part of the process has also fueled the discussion. Culture is cited as the container that holds the leadership process. This is to say that neither leadership nor culture can be understood by itself (Schein, 1992). When the idea of re-engineering the corporation was introduced by Hammer and Champy in 1993, the organizational process was in the spotlight. This was a rational process based on flowcharts, decisions, tasks, events, data, documents, and the beginning and ending events; but leadership process involves more than just linear development of tasks and activities. For many, culture becomes the bed or the container on which the leadership process takes place. This argument can be depicted from the following statement:

"The leadership process is like a river. Contained by its bed (the culture), it can be said to be flowing in one direction, yet, upon close examination, parts of it flow sideways, in circles, or even backwards relative to the overall direction. It is constantly changing in speed and strength, and even reshapes its own container. Under certain conditions, it is very unified in direction and very powerful; under other conditions, it may be weak or may flow in many directions at once". (Barker, 1997, p. 8).

These arguments then take us to the conception of a social process in which leadership resembles a nonsupervisory relationship that is dynamic and mutual. Social process involves an encompassing or molar meaning. It includes social relations, role, and role expectations. According to Barker, leadership relationships are based in role expectations and are contractual, and leadership process serves as the vehicle for creating leadership relationships. Therefore, it is not the leader who creates leadership; it is leadership that creates the leader. (1997). Under this perspective the leading act generates the leader who is a resulting outcome of the leadership process. Moreover, this reasoning of leadership says that the leader is strongly influenced by the collaborators while they work together to achieve an important goal. This conceptual set leads to certain philosophical concepts. The summum bonum, defined as the supreme good from which all others are derived, represents an ultimate goal or end at which all human actions are directed. Both Aquinas and Aristotle conceived this end as necessarily connected to happiness. This implies that followers engage in actions that produce in them a sense of willingness and joy and, with this momentum, a leader is created to conduct the leading act, thus triggering the leadership process. Subsequently, interactions and tasks seeking a group-desired outcome take place.

The audience likely to benefit from this study is basically users and producers of research findings. More specifically, the audience includes academic circles and faculty who have the responsibility of preparing leaders and actual practitioners of organizational leadership. Students of organizations, management, and leadership will have the opportunity to challenge existing or traditional conceptions of organizational theory and develop their own concepts of leadership. In addition, this study will provide useful information for executives, administrators, and team members from a variety of organizations.

\section{PURPOSE}

The purpose of this investigation was to identify the most effective follower attributes within a leadership process as perceived by the followers themselves and by the leaders.

\section{RESEARCH QUESTIONS}

1. What are the critical personal attributes of followers participating in a leadership process?

2. Is there a set of distinct attributes of followers, as perceived by leaders, that is important to the process?

3. Is there a difference between the necessary personal attributes perceived by leaders and those identified by the followers themselves?

4. Is there a difference in important personal attributes of followers for the leadership process perceived by leaders and followers from select countries/cultures (Italy, Mexico, Bolivia, Brazil, Republic of Korea, and USA)?

5. Do leader attributes influence follower attributes in the process and vice versa? 


\section{RESEARCH DESIGN}

This exploratory study of the leadership process, in terms of the followers, calls for a survey research design. The identification and measurement of effective attributes can be accomplished by following a quantitative approach to research and utilizing perceptual instrumentation to collect the pertinent data from a sample of participants.

\section{Participants}

The targeted population is represented by leaders and followers who are actually engaged in a leadership process. Participants of this study were comprised of followers that are members of work-groups in different professionally managed organizations from the USA, Italy, Mexico, Republic of Korea, Taiwan, Brazil, and Bolivia. These organizations were selected from sectors, such as education, business, nonprofit institutions, health care services, government agencies, professional associations, and social or political organizations. A sample of 100 participants from each of the participating nations were utilized to complete this study, as it is ongoing and the results are preliminary. The overall size for the completed study will total 600 subjects.

\section{Instrumentation}

The following survey instruments were used to measure the subjects' responses as the tool of data collection for this study:

1. Leadership as a Process: Follower Attribute Inventory. Follower Self Assessment, Form 1. (FAI-FSA-1).

2. Leadership as a Process: Follower Attribute Inventory. Leader Assessment of Follower, Form 2. (FAILAF-2).

A literature review conducted on personal characteristics of leaders and followers produced a list of their most common attributes. These results were used to construct an instrument assessing leaders' attributes. This instrument has been validated and subjected to Cronbach's alfa analysis with acceptable reliability (.885) (Henderson \& Antelo, 2007). A subscale of this questionnaire includes personal attributes of the followers, who are also utilized to collect data for this study.

This instrumentation will/has allowed the researchers to identify and describe personal attributes of followers in terms of the perception of the participating leaders, as well as the followers themselves. The instrument will be posted online and respondents who are leaders and/or followers will have access to the questionnaire and thus reply online to the Surveymonkey system.

\section{DATA ANALYSIS}

Data gathered by this endeavor has followed (and will follow) this specific research design. Procedures of descriptive statistics will continue on the collected data for identifying the follower attributes. Measures of central tendency, variability, and correlation coefficients will also continue to be computed and analyzed by means of the SPSS program, version 16.

\section{Protection of Human Subjects}

Guided by purposes for the protection of human subjects, before the data are collected, the researcher will obtain permission from the Institutional Review Board of the University of the Incarnate Word. Clearly, participation in this study is (and has been) completely voluntary and, as a result, the sample is comprised of leaders and followers who are actually working in existing organizations in different nations of the globe and whose decision to participate is solely up to them. In this light, individual participants will receive a consent form explaining the purpose of the study, as well as respondents' rights, benefits, and risks involved in the investigation. In addition, participants will continue to be assured of the confidentiality of their responses and complete anonymity will be maintained throughout the process. We hope that these actions will continue to motivate truthful responses 
on the part of the participants and that no one will feel threatened to provide an answer in one way or another. Personal information or demographic data will be kept confidential and only group data will be used to fulfill the purpose and answer the study research questions.

\section{PRELIMINARY RESULTS}

The main factors included in the instrumentation were:

1. Facility for interpersonal relations concerning relationships between people.

2. Facility for group relations and functions concerning the infrastructure or means to form a cohesive group or unit.

3. Tolerance concerning acceptance of the differing views of other people.

4. Conceptual understanding concerning the ability to use knowledge, reasoning, intuition and perception.

5. Facility for earning and embracing change concerning the process of solving a question or puzzle, difficulty, or situation.

6. Facility for effective communication concerning accurate exchange of information between or among people.

7. Reliability as a group member concerning the ability with the creation of patterns and the capacity to solve organizational problems.

8. Facility for contribution to the group concerning the ability to use the imagination to develop new and original ideas or things.

9. Emotional intelligence concerning personal attributes that enable people to succeed in life, including selfawareness, empathy, self-confidence, and self-control.

10. Facility for supporting others concerning a picture of likeness of someone or something produced either physically or formed in the mind of the beholder.

11. Flexibility concerning the ability to change or be changed according to needs or circumstances.

12. Motivation for goal accomplishment on a variety of projects concerning the biological, emotional, cognitive, or social forces that activate and direct behavior.

\section{CONCLUSION}

Results indicate that perceptions of leaders and followers regarding effective leadership attributes of followers are different. One of the assumptions held by this study was that a similar degree of effectiveness perceived by both the leader and the follower will determine a measure of effectiveness of the follower's attribute under analysis. Conversely, differences on the perceptions will show the degrees of ineffectiveness of the attribute. This will lead to a number of implications, such as the need for training, team building, group cohesiveness, leadership development strategies, and programs aimed at improving and clarifying the leadership process.

Effective communication, or the ability of the follower to engage in accurate exchanges of information between or among people, was the attribute receiving similar perception of both the followers themselves and the leaders. Major discrepancies have, to date, been found in those attributes related to reliability as a group member, facility for contribution to the group, and emotional intelligence.

\section{AUTHOR INFORMATION}

Dr. Richard L. Henderson has teaching and administrative experience in private as well as public education and as a consultant for a variety of human service institutions and private corporations. He served as Coordinator for Educational Administration at the University of Texas at San Antonio. He served as Chair for Educational Administration and Supervision Graduate Programs at the University of Arkansas, Little Rock for six years where he also received the Faculty Excellence in Teaching award. His research and writing is published in international as well as national and regional journals.

Dr. Norman St. Clair currently serves as a member of the doctoral faculty and Director of Graduate Studies in the Dreeben School of Education at the University of the Incarnate Word (UIW). His fields of expertise and research 
agenda are focused in the areas of International Education and Entrepreneurship and Leadership. Before assuming his current responsibilities, Dr. St. Clair served as Director of International Initiatives for 5 years at UIW and was the founding On-site Academic Director for UIW's China Incarnate Word campus in Guangzhou, China, where he lived and served for 5 years.

Dr. Absael Antelo comes from a family of educators devoted to the advancement of education. He has extensive teaching and administrative experience in institutions of higher learning, common schools, and in business organizations both domestically and internationally. He has served as university president, school superintendent, academic vice president, university professor, and as an executive of a textile industrial group. Currently he is an Associate Professor and Coordinator of the Higher Education concentration in the Dreeben School of Education's $\mathrm{Ph} . \mathrm{D}$. program at the University of the Incarnate Word. His research agenda and publications include leadership, followership studies, and intercultural learning.

\section{REFERENCES}

1. Barker, R. (1997). How can we train leaders if we do not know what lesadership is? Human Relations, New York: April 1997. Vol. 50 (4), 343.

2. Dvir, T. \& Shamir, B. (2003). Follower developmental characteristics as predicting transformational leadership: A longitudinal study. The Leadership Quarterly, 327-344.

3. Erdman, Richard (2004). Leadership as a process. Retrieved February 20, 2008, from http://www.syfrcorp.com/presentations/RooseveltBanking.html

4. Hammer, M. \& Champy, J. (1993). Reengineering the corporation: A manifesto for business revolution. New York: Harper Business. A Division of HarperCollins Publishers.

5. Méndez-Morse, S. (1992). Leadership characteristics that facilitate change. Retrieved from http://www.sedl.org./pubs/items/cha02.html

6. Schein, E. H. (1992). Organizational culture and leadership. (2 $2^{\text {nd }}$ ed.) San Francisco: CA: Jossey-Bass.

7. Rost, J.C. (1991). Leadership for the twenty-first century. New York: Praeger.

8. Yammarino, F.J. (1995). Dyadic leadership. The Journal of Leadership Studies. 2(4), 50-74. 